\title{
Una nueva mirada desde los límites de lo irreal: la fusión de categorías genéricas en la escritura de la imaginación de Juan Jacinto Muñoz Rengel
}
A New Perspective on the Limits of the Unreal: The Fusion of Generic Categories in the Writing of Imagination by Juan Jacinto Muñoz Rengel ${ }^{1}$

\author{
Natalia Álvarez Méndez \\ Universidad de León \\ natalia.alvarez@unileon.es
}

\begin{abstract}
Juan Jacinto Muñoz Rengel (1974) is one of the greatest exponents of the hybridization of the fantastic with other non-mimetic modalities and with popular genre narratives. The mestizaje characterizes, through juxtaposition or fusion, much of his work, generating the ultimate significance of a broader scope. The fantastic is intertwined with adjacent categories, including science fiction, terror and magical realism. It is also commonly combined with the historical, detective, adventure or humorous narrative styles. He merges these diverse modes of invention by transgressing the rigid and normative molds with the aspiration of constructing new literary options. The dissolution of frontiers between the fantastic and other neighboring genres is also potentiated with frequent intertextual nods and suggestive tributes to the traditions of the unusual.
\end{abstract}

Keywords: Muñoz Rengel, hybridisation, the fantastic, science fiction, horror, magical realism

En los estudios que delimitan los resortes de lo fantástico en la literatura española actual (Álvarez Méndez, 2013; Roas, 2015; Abello Verano, 2016; Roas, Álvarez

\footnotetext{
${ }^{1}$ Este trabajo se ha desarrollado dentro del Proyecto de Investigación Lo fantástico en la literatura, el cine y la televisión fantásticos españoles (1955-2013). Teoría e historia (FF12013-44152-F) del MINECO.
} 
\& García, 2017) Juan Jacinto Muñoz Rengel figura en la nómina de escritores destacados. Es uno de los nombres consagrados de dicha categoría estética, en la que despunta por la originalidad y por la seriedad de su obra, derivadas ambas de su concepción de lo fantástico que "no puede entenderse sino desde una aproximación filosófica" (Muñoz Rengel, 2015, p. 19). Mediante su faceta creadora, y también con su quehacer crítico, lleva a cabo una incontestable defensa del valor de la literatura fantástica, divergente de la maravillosa y concebida como la representación de un mundo natural trastocado en algo extraño (v. Jackson, 1981). Muñoz Rengel demuestra que este tipo de producción artística es un instrumento totalmente válido para indagar en la realidad, un cauce con el que consigue imprimir en sus historias "la marca de la preocupación filosófica, epistemológica, metafísica [...], y aumentar las posibilidades ficcionales e imaginativas de los relatos" (Muñoz, 2011, p. 224). No en vano, tal como postula Ceserani (1999), la modalidad fantástica ha servido en cada periodo concreto

para extender y ensanchar las áreas de la "realidad" humana interior y exterior que pueden estar representadas por el lenguaje y por la literatura y, aún más, para poner en discusión las relaciones que se establecen en cada época histórica, entre paradigma de realidad, lenguaje y nuevas estrategias de representación. Se trata, conviene añadir, de estrategias no sólo representativas, sino también cognoscitivas. (p. 100)

Con la seguridad de que desde ese anclaje estético -a pesar de los prejuicios críticos a los que ha estado sometido- se puede hacer gran literatura, desecha la vertiente puramente representativa y fabula hasta límites que abocan a una original superación de etiquetas genéricas. Su singular poética tiene su germen en la mixtura de categorías próximas a las fronteras de lo fantástico y a manifestaciones consideradas como narrativas de género. Si la mayor parte de sus ficciones se adscriben a lo fantástico, siendo la perturbación de la realidad una coartada para ahondar en esta última y en la identidad, su empleo de lo irreal no se detiene en esa vertiente. A través del hibridismo busca una técnica que le permita avanzar en su creación alcanzando una mirada nueva. De tal modo, se ha convertido en uno de los máximos exponentes de la hibridación de lo fantástico con otros géneros y categorías, recurso que empieza a descollar en el panorama de la última narrativa española no mimética (Roas, Álvarez \& García, 2017, pp. 208-211).

Ese mestizaje se hace evidente en la conjunción genérica que caracteriza gran parte de su obra, gestando un significado último de mayor alcance a través de la yuxtaposición o de la fusión. Lo fantástico enlaza con manifestaciones fronterizas, entre las que destacan la ciencia ficción, el terror y lo real maravilloso, y se enmarca, además, en el relato histórico, policíaco, de aventuras y de humor. Muñoz Rengel compagina esos diversos grados de fabulación transgrediendo los moldes rígidos y normativos con la pretensión de construir hallazgos literarios: “[...] fusionar géneros de una manera que nunca antes se hubiera hecho, o incluso cruzar aquellos géne- 
ros que era antes impensable plantearse asociar [...], a mí me resulta estimulante" (Álvarez, 2016, p. 61). Su intención focaliza ese camino literario: "creo que cruzando géneros se puede mirar un poco más lejos, mirar hacia otro lado, hacia algún lugar que quizás aún no se ha llegado a señalar con el dedo" (Álvarez, 2016, p. 61). A ese punto de partida se une la interiorización previa de las diversas tradiciones de lo insólito, lo que le permite crear su propio mundo artístico y enriquecerlo rindiendo tributo, a su vez, a grandes maestros del género. Así lo demuestran los guiños intertextuales y los sugestivos homenajes a obras de reconocidos escritores, consideradas por Muñoz Rengel como piezas con las que trabaja desde la capacidad de recombinación, deformación y suma (Álvarez, 2016, p. 56).

Si su segunda novela, El sueño del otro (2013), no abandona los márgenes de lo puramente fantástico, hay que recordar que la primera, El asesino hipocondríaco (2012), su obra más distanciada de dicha estética, pone de manifiesto su interés en mezclar discursos -históricos, científicos, diarios, testamentos-, así como en emplear novedosas estructuras y categorías como lo extraordinario, el humor y el género negro. En esos primeros años de trayectoria son, sin embargo, sus libros de cuentos y de microrrelatos el exponente de la yuxtaposición y fusión de géneros. $88 \mathrm{Mill}$ Lane (2005) combina la tradición fantástica victoriana -Stevenson, Chesterton, James, etc.- con la borgiana, abordando lo metaliterario, lo onírico, la inmortalidad, lo histórico, lo policíaco, el destino, la predestinación, lo monstruoso, la percepción del mundo a través de los sentidos y los universos autocontenidos. Por su parte, el volumen de microrrelatos El libro de los pequeños milagros (2013) conforma una interesante estructura en la que su división en secciones -"Urbi", "Orbe" y "Extramundi"- plantea propuestas significativas de lectura que se complementan con lo referido en los títulos, los índices y los anexos. Mediante ese procedimiento se conjuga lo fantástico y lo futurista, a lo cual se suma la tradición del bestiario. Se reflexiona sobre la identidad, el doble, cuestiones metafísicas, los límites de nuestra realidad, de los sueños, la relatividad del tiempo, la monstruosidad y un largo etcétera, con una visión crítica de nuestra sociedad y sus diversos problemas.

Pero es su segundo volumen de cuentos, De mecánica y alquimia (2009), aquel que sobresale con una estructura sostenida por múltiples puentes de conexión que trenzan lo fantástico con lo histórico, lo científico y lo filosófico, y con otras categorías fronterizas como el terror, las historias de fantasmas y la ciencia ficción prospectiva con lo distópico y lo apocalíptico. El conjunto de once relatos, sumados a las advertencias iniciales y finales, desvela sugerentes técnicas de engranaje de un artefacto creativo en el cual todo encaja a la perfección. Todo ello posibilita el acceso a interesantes niveles de lectura que enriquecen el sentido de los diversos ejes temáticos sobre los que giran sus tramas: el dualismo filosófico, la separación entre mente y materia, la creación de vida artificial, el avance de la tecnología, junto a la magia, las profecías, los sortilegios, las metamorfosis, los espectros, así como los monstruos orgánicos y no orgánicos que amenazan a la humanidad. Presenta una 
aproximación a la Historia del ser humano y del conocimiento en el ámbito europeo, desde la Edad Media al futuro venidero. Asimismo, como afirma el mismo Muñoz Rengel, estructura el libro "como un repaso cronológico a distintas tradiciones narrativas propicias al cuento fantástico. Desde una historia chestertoniana que se desarrolla en el Toledo musulmán hasta varios cuentos plenamente de ciencia ficción"; "creo que también podría haber algo del humor -en algunos tonos y diálogos- que inicia G. K. Chesterton, y algo del gusto por el juego de Lewis Carroll" (Muñoz, 2011, p. 224). Pretende ofrecer algo nuevo, pero sin renegar de los precedentes, y es por ello que no duda en ubicarse en la línea de cuentistas de "Hoffmann-HawthornePoe-L'Isle-Adam-James-Maupassant-Kafka-Cortázar-Borges-Calvino" (Muñoz, 2011, p. 230). Es innegable, además, la intertextualidad con determinadas obras de Lovecraft, Bioy Casares, Asimov, Bradbury, Lem y K. Dick, entre otros. Todo ello ha propiciado que haya sido reconocido también por la crítica académica y especializada como autor de "algunos de los mejores relatos de cf actuales" (Díez \& Moreno, 2014 , p. 96), pertenecientes a la literatura prospectiva, aquella que ofrece una reflexión crítica y especulativa desarrollada de forma estética (Moreno, 2010, p. 118).

Su novela más reciente, El gran imaginador o la fabulosa historia del viajero de los cien nombres (2016), es la obra en que la mixtura genérica alcanza su punto más álgido y rotundo. No en vano, ha recibido el Premio a la Mejor Novela en castellano 2017 del Festival Celsius, que celebra el terror, la fantasía, la ciencia ficción y géneros próximos. No es, como en los casos anteriores, un libro de cuentos o de microrrelatos que conjuga categorías genéricas gracias a sus diferentes títulos o secciones, sino que ofrece la narración de la historia de un mismo personaje que se sostiene sobre el ensamblaje impecable de estéticas variadas. No se podía esperar menos de un escritor que en todas sus ficciones ha planteado un sólido imaginario aderezado por interesantes novedades -singulares propuestas discursivas, sorprendentes elecciones de protagonistas y de narradores, complejas estructuras, variados registros y diversos estilos-, así como por la mezcla de modalidades genéricas guiada por la defensa de lo fantástico y de las múltiples posibilidades de la literatura de la imaginación, sin acomodarse en ningún caso a una fórmula recurrente.

Muñoz Rengel (2015) define la ficción como una herramienta de conocimiento que nos permite construir nuestra versión del mundo, contarnos, comprendernos, y profundizar en la naturaleza del tiempo y del espacio, en la identidad y la muerte (pp. 20-21). Si partimos del hecho de que nuestra percepción y elaboración de la realidad se lleva a cabo a través de mecanismos de ficción, no cabe duda de que debemos recelar del relato histórico conocido. Como señala el mismo Muñoz Rengel, De mecánica y alquimia se enfrentaba a la historia del conocimiento europeo, de la ciencia, tomando como justificación que "la technos, la tecnología [...] entendida como manipulación del mundo, nace en Grecia, y se desarrolla en la cuna de Occidente" (Muñoz, 2011, p. 229). El gran imaginador avanza más en esta visión y reconoce las deudas de la cultura occidental con las tradiciones del Lejano Oriente, del 
Imperio Otomano. Ese ideario le obliga a adentrarse en una época complicada, la del siglo XVI, en la cual se ubican los inicios de la modernidad. Y en una no menos compleja geografía, muy bien retratada en sus ambientes y en sus referencias culturales y sociales, que abarca Oriente y Occidente -las costas griegas, Atenas, el Monte Athos, Malta, Estambul, los Balcanes, Rumelia, Albania, Serbia, Croacia, Valaquia, Transilvania, Praga y Argel-. En ese escenario pone de relieve, a través de diversos motivos, las diferentes formas de falsificación en la construcción de la Historia, sin olvidar la denuncia de determinados intereses religiosos, políticos y, cómo no, económicos.

El trabajo de documentación es ingente, cosa que aboca a un magnífico resultado donde la sucesión de aventuras se encuadra en un contexto de datos históricos -con leves anacronismos justificados en el "Escolio"- y de apuntes geográficos fidedignamente contrastados que se unen a una prosa brillante. Sus cambios de tono y de registro permiten adecuarse a cada momento relatado, de igual modo que lo posibilita la elección de un narrador tradicional y omnisciente en tercera persona. De manera mágica, y sin olvidar el humor como compañero de viaje, lleva al lector de la mano a un mundo exuberante en lo objetivo y en lo íntimo, en las perspectivas más amplias y en los pequeños detalles. Los diversos pasajes estimulan la mente o sorprenden y entretienen en función de la situación narrada y del momento temporal al cual nos enfrentan los saltos en el discurrir de la historia.

Pero, en la mente de un gran imaginador como Muñoz Rengel, lo estrictamente realista no es suficiente para crear. Por tal motivo, la fabulación tiene una gran fuerza y entra de lleno en esa trama histórica y de aventuras para enriquecer su sentido mediante una suma de géneros no miméticos que se asientan en lo fantástico y sus fronteras. De tal modo, nos sitúa ante una novela histórica que, a su vez, ha de ser definida de forma amplia como un relato fantástico integrado en un sólido contexto realista. Con ella logra hablar de la vida, pero también de la ficción, demostrando de forma magistral su tesis de que esta última nos proporciona el medio para conocer la realidad.

El protagonista, Nikolaos Popoulos, escritor inédito y fabulador interior, incomprendido y rechazado en el ámbito familiar y en el social por sus peculiaridades, contiene dentro de sí universos completos, una mente laminada y extraordinaria que le adelanta a su tiempo y le permite trascender dimensiones, visionar y soñar civilizaciones futuras de nuestro planeta y extraterrestres, además de dar una explicación nueva a los hechos conocidos de la Historia. Su descubrimiento de la ficción literaria le hace consciente de "un mundo independiente de las cosas materiales, en el que todo estaba permitido" (Muñoz Rengel, 2016, p. 28). Este hecho potenciará sus dudas sobre la realidad, a la que considera afectada por la ficción.

[...] Nikolaos entendía la realidad como algo infinitamente más vasto que aquello que le llegaba por los sentidos. El arte de imaginar, o de combinar términos, números e inter- 
pretaciones, al igual que hacían los alquimistas mezclando sus sustancias, era la única forma sensata de estar en el mundo. (Muñoz Rengel, 2016, p. 410)

Las reflexiones sobre la dificultad de separar lo cierto de lo falso se conjugan con el grado de verdad que se le concede a los recuerdos y a los sueños, y con la consideración del saber -la teología, por ejemplo- como una prolongación de la ficción, de la literatura fantástica. Desde la perspectiva de los géneros no miméticos, por lo tanto, se acota la preocupación por cómo se construye no solo nuestra realidad, sometida al juego de espejos, al simulacro, sino nuestra identidad, y por cómo se edifican ideas abstractas como el Mal, la Nada y la Verdad. El poder de la imaginación es grandioso, como se transmite gracias a pasajes protagonizados con el fiel amigo de Popoulos, Mixalis Phanerotis, que parece esperar siempre al personaje principal en el puente que separa la realidad de la ficción. La inexistencia de Phanerotis se comunica muy avanzada la novela, desvelando que su introducción en la misma encarna y simboliza, tal como pone de relieve la explicación de su etimología en el "Escolio", no solo los fantasmas, las visiones y los sueños sino también la fantasía y lo fantástico.

Conviene recordar que las distintas modalidades de literatura no mimética han sido agrupadas erróneamente durante mucho tiempo por parte de algunos especialistas bajo un mismo marbete o categoría genérica, hecho en el cual han incidido diversos estudiosos con el fin de clarificar dicha teorización. Así se sintetiza en Reisz (2001), Roas (2011, pp. 43-78; 2014) y Gregori (2015, pp. 21-84). En esa línea y llegados a este punto, no es válido decir que El gran imaginador es una novela fantástica en la que se intercalan episodios de otras estéticas. Es necesario profundizar más en la problemática de su adscripción genérica. La extraordinaria habilidad del protagonista -su poder de imaginar sin ningún tipo de límites que se pone de relieve en la narración de aventuras y en el relato de infancia con estructura de Bildungsroman- ofrece distintos planos de realidad que hacen fluctuar la narración desde lo fantástico a otra vertiente de lo insólito. En concreto, se podría hablar de una variante cercana, salvando las distancias, al conocido realismo mágico hispanoamericano (v. Abate, 1997), una forma híbrida entre lo fantástico y lo maravilloso. Por un lado, lo fantástico prevalece ante los ojos del lector frente a una explicación racional y científica que se ofrece en un momento dado en la narración, pero que inmediatamente es puesta en duda por ser una de las múltiples intuiciones que pasa por la mente del personaje sin certeza de autenticidad. De ello se deriva que la tesis fantástica que sostiene el armazón histórico y de aventuras de la trama se mantenga en pie, pues "se construye a partir de la convivencia conflictiva de lo real y lo imposible" (Roas, 2011, p. 45). Por otro lado, la aceptación por parte del narrador de las características singulares de Popoulos permite la introducción de episodios extraordinarios, prodigiosos, que son concebidos como normales por dicha entidad narratológica, a pesar de su imposibilidad en el mundo real donde se desarrolla la 
acción. Este hecho nos acercaría a lo real maravilloso o realismo mágico (v. Llarena, 1997), que "plantea la coexistencia no problemática de lo real y lo sobrenatural en un mundo semejante al nuestro" (Roas, 2014, p. 21).

Muñoz Rengel (2016) construye, por lo tanto, una nueva mirada, situándose en un molde genérico híbrido que surge como fruto de aunar lo histórico con lo insólito, de concebir la fabulación como eje de nuestra realidad, en la que "- La ficción lo es todo" (p. 310). El escolio final, que obliga a ser leído ante un espejo por su disposición inversa, trata de reafirmar dicha idea dotando al libro de la entidad de los tratados científicos de la época. Su objetivo también se ve reforzado por el homenaje que rinde a Cervantes, creador de El Quijote, obra que inaugura la novela moderna y que destaca por la mixtura genérica a través de la metaliteratura, el humor, la parodia de las anteriores novelas de caballería y otras manifestaciones, así como la inclusión del cuento y la poesía.

Cervantes se convierte en un relevante personaje secundario con el cual se abre la novela gracias a su encuentro con el protagonista en la batalla de Lepanto. Con él se introduce en el libro no solo al citado escritor real, sino también la reflexión acerca del poder de la fabulación y la genialidad creativa. Se incide en la figura del escritor adelantado a su época y en su lucha por conseguir dedicarse al quehacer literario a pesar de las dificultades impuestas por la vida. El paralelismo es evidente, ya que el protagonista, defensor de las causas perdidas, se ve perseguido por la maldición de ser un hombre de acción que no encuentra tiempo para escribir y, en las pocas ocasiones en que lo hace, su obra acaba perdiéndose por los azares de la vida. Como homenaje, Cervantes llevará el apellido Saavedra, que es uno de los empleados por Popoulos en sus últimas aventuras. Reencontrados en Argel, Popoulos le cuenta su vida a Cervantes, le narra la novela El gran imaginador, intuyendo e inspirando la futura obra universal del español con historias pasadas y futuras. Como resultado de su encuentro, la imaginación, la maquinaria de la ficción, será el arma utilizada por ambos para salir exitosos de las aventuras emprendidas.

El origen de El Quijote y parte de su contenido se anticipa en la narración de las vivencias de Cervantes y Popoulos, como el motivo de la bacinilla a modo de yelmo (Muñoz Rengel, 2016, p. 20); un poblado con debates entre el cura y el barbero (p. 219); la idea de incluir en la narración mujeres bellísimas, aunque sean porquerizas y criadas o pastoras de pequeñas aldeas (p. 302); y la alusión a las nubes que parecen molinos de viento (p. 322). Con la idea de la metaliteratura juega también Muñoz Rengel, pues una de las falsas credenciales de Popoulos lo identifica con un morisco llamado Hamete Berengeli, directamente relacionado desde la metaficción con la autoría de El Quijote, siendo otra de ellas la de Agi Morato, personaje de la misma obra. A su vez, son recurrentes las imágenes literarias que nos ofrecen un dibujo de las figuras de don Quijote y Sancho, aunque con algunos de sus rasgos físicos intercambiados, cual reverso, en el perfil de Nikolaos Popoulos y Mixalis Phanerotis, que en un cuento escrito por el primero recorren tierras extranjeras "des- 
haciendo entuertos y auxiliando a los más débiles” (Muñoz Rengel, 2016, p. 155); y, tal como se manifiesta más adelante, cabalgan de modo que "sus tristes figuras sobre los caminos de tierra del bosque iban de lo grotesco a lo estrafalario y de lo estrafalario a lo risible" (p. 325).

Desde ese peculiar punto de partida, en el cual se plantea la disolución de los límites entre lo real y lo ficticio, lo fantástico logra entrelazar lo filosófico con lo popular y lo lúdico. A ello se añade la desmedida capacidad imaginativa del protagonista, que permite sumar a la trama otras variedades de la literatura de la imaginación, entre ellas el terror y la ciencia ficción. La fabulación mental de Popoulos es un espejo de la inteligente apuesta literaria de Muñoz Rengel (2016), quien, de modo paralelo a su propio personaje, mezcla categorías diversas en su novela, siendo consciente de los personajes, situaciones y escenarios, así como de diferentes enfoques, técnicas narrativas, estilos y evocadoras palabras, todo ello aunando ideas de índole filosófica, de esparcimiento, fantásticas, realistas, humorísticas, románticas, estrambóticas, terroríficas y referidas a planetas lejanos (p. 193).

De nuevo en un contexto metaficcional, los tres cuentos que escribe de adulto el protagonista de El gran imaginador anticipan el discurrir de hibridismo genérico de la novela, ya que potencian la intertextualidad y los juegos entre realidad y ficción. El primero de ellos recrea una investigación criminal y fantástica, con guiños evidentes a El nombre de la rosa, que lleva por título La abadía del crimen. Dicha denominación coincide con la de un videojuego español de finales del siglo $\mathrm{XX}$, basado en la misma novela, que rompió barreras en su sector combinando lo histórico con recursos futuristas. El segundo, que recoge las aventuras del propio Popoulos, es una trama mudable vivida por un caballero y su escudero, quienes recorren tierras extranjeras enfrentándose a enemigos y monstruos de geografías del norte. Dicho relato conjuga la comedia disparatada con las aventuras, así como con una historia de amor y de horror. Y el tercero se encuadra en la literatura de terror, enlazando las leyendas sobre vampiros con el horror cósmico y la mitología de Lovecraft. Remite a formas monstruosas, perceptibles por vez primera en los montes Cárpatos, con habitantes que asesinan y se beben la sangre de sus víctimas, surgidas del culto atávico a una oscura criatura, "un organismo ancestral, destructor de mundos, que latía desde antes del principio de los tiempos en las profundidades del planeta" (Muñoz Rengel, 2016, p. 156). Aludiendo a la entidad cósmica de Cthulhu, compara esas figuras terroríficas con los tentáculos de un ser supraterrestre, apéndices monstruosos de una gigantesca criatura que provoca la pérdida de la cordura y de la vida.

En suma, los relatos escritos por Popoulos demuestran su interés particular por las historias de otros mundos y de terror. En su cabeza se proyecta "todo un firmamento de seres imposibles y de orbes con sus propias leyes, que cada vez adquiría más forma y más peso" (Muñoz Rengel, 2016, p. 116). En una marcada obsesión por lo extraterrestre, visiona planetas, las conexiones entre estos y los seres que los habitan. No extraña, por lo tanto, su fascinación por las fábulas del mundo antiguo sobre 
los viajeros espaciales, figura a la cual él mismo parece asimilarse por su capacidad para percibir las múltiples dimensiones de nuestra realidad, planteadas recientemente por la teoría de supercuerdas, y por su defensa de lo minúsculo como medio que nos puede llevar a que cambie "para siempre la forma de pensar o de ver el universo" (Muñoz Rengel, 2016, p. 94). Las referencias de Popoulos a obras de la protociencia-ficción de su tiempo, como los Relatos verídicos de Luciano de Samosata, entre otras, se conjugan con su interés por la vida en la Luna y la condición de los seres de otros planetas, materializando un homenaje a los orígenes griegos del género, tal como reconoce en el "Escolio".

No extraña, por ello, que la novela sorprenda en la tercera parte con un particular homenaje a La guerra de los mundos de H. G. Wells, enfrentando al protagonista a la invasión extraterrestre de la capital del Imperio Otomano, Estambul, considerada como el centro de la civilización y dedicada por aquel entonces a la ciencia astronómica y los artefactos de medición del tiempo. Las naves flotantes del pueblo invasor, como órganos latientes, y sus planes para conquistar al mundo, son descubiertas por Popoulos, así como la existencia de seres, también en la estela lovecraftiana, que emiten zumbidos y llevan antenas de insecto vibrando en la cabeza, capaces de hacer perder la voluntad a aquellos que los miran. Se libra entonces la gran batalla entre dos mundos: el humano que ha de defenderse con las armas propias de su ciencia, como el fuego griego existente en el ámbito bizantino, y el alienígena que domina las dimensiones temporales y espaciales, que posee una anatomía monstruosa y objetos desconcertantes que se oponen a las leyes de la naturaleza. Los extraterrestres, sin embargo, no parecen tener el más mínimo interés en invadirlos, como si "estuvieran colocando sus cosas, sin reparar en sus diminutas existencias" (Muñoz Rengel, 2016, p. 282). Todo esfuerzo humano para combatirlos es inútil, a pesar de las armas basadas en la fusión de la mecánica con la alquimia, de las válvulas con la ciencia esotérica. Los invasores se alejan del planeta solo cuando les llega el mensaje de que están molestando y el recuerdo de lo vivido queda borrado desde ese momento de las memorias humanas.

A la ciencia ficción le sucede el terror. Popoulos viaja en la cuarta parte por tierras de Bulgaria, Macedonia, Rumelia, Albania, Serbia, hasta llegar a Valaquia, donde se habla de tinieblas, de supersticiones y de extrañas muertes que aterrorizan a consecuencia de lo que parece la conversión de los lugareños en strigoi. Esas vivencias son el germen de una historia escrita por Popoulos, titulada El extraño misterioso, en la cual, según el narrador de El gran imaginador, se emplea por primera vez en literatura el término "vampiro" para definir a esos seres. A su vez, en la novela se alude explícitamente al personaje histórico de Vlad Drăculea, príncipe de Valaquia e inspirador del mito de Drácula, a su forma de combatir a los turcos y a su imagen retratada históricamente como la de un monstruo. Todo ello conduce desde los Cárpatos a Transilvania y al encuentro del protagonista con otro personaje real conocido por sus sádicos crímenes, Erzsébet Báthory, la Condensa Sangrienta. Tras 
esa vivencia, Popoulos recuerda obsesivamente el abominable castillo de los Cárpatos Occidentales y su condesa erigida en un monstruo innombrable. A partir de ese instante ya no podrá vivir en la ignorancia del mal. Pesa sobre él el terror a los juegos macabros, a las mujeres abyectas y a los sótanos del horror.

Lo monstruoso no se detiene en las historias de vampiros, pues se manifestará en diverso grado a través de otra figura legendaria también relacionada con la protociencia-ficción. Así sucederá en la quinta parte de la novela, en la corte de Praga integrada por astrónomos, botánicos y matemáticos, pero también por alquimistas, magos, astrólogos, pintores y artistas. En la ciudad conocida por su fascinante reloj astronómico, concretamente en el Barrio Judío, es creado el gólem, monstruo de barro, por el Rabbi Judah Loew, personaje histórico, hombre de gran cultura y conocedor de la Cábala. La vida artificial del gólem, personaje de leyenda destinado a defender al pueblo judío, se origina a través del lenguaje, de la combinación de caracteres sagrados. Pero Muñoz Rengel renueva el motivo de la criatura artificial, gestada a imagen y semejanza del hombre, que se rebela contra la voluntad de su creador. Lo perfila como un ser que se siente humano y que, con motivo de un mal de amores, experimenta deseos de venganza contra la humanidad. De tal modo, el gigante de barro destruye la ciudad, multiplicándose en numerosas criaturas bifurcadas, hasta que finalmente se une de nuevo y se sumerge en el fondo del río. Muñoz Rengel actualiza en este episodio el motivo clásico del doble (v. Coates, 1988), que pone de relieve las alteraciones fantásticas de la identidad sembrando la duda sobre la integridad individual y nuestra propia realidad. La metaliteratura y el juego entre realidad y ficción continúan, puesto que estos acontecimientos inspiran una narración del protagonista, El hombre de barro, protagonizado por Nathanael, un estudiante de artes impías, que crea un monstruo que se rebela y escapa de su creador. Según la novela, este relato, con explícitas reminiscencias de El hombre de arena de Hoffmann, junto a El extraño misterioso escrito por Popoulos en el castillo de los Cárpatos, se publica siglos después en un volumen de cuentos de terror alemanes, inspiradores nada menos que de la noche en que surge el germen de los mitos de Drácula y de Frankenstein a orillas del lago de Ginebra.

La sintética aproximación realizada al empleo híbrido de lo fantástico y otros géneros fronterizos en El gran imaginador también ha de dejar constancia de la intertextualidad como recurso constante de la novela. En ella se suceden títulos clásicos, como el Poema de Gilgamesh, Índica de Ctesias de Cnido, Physiologus, Las mil y una noches, y referencias (más o menos explícitas en cada caso) a Aristófanes, Homero, Poe, Borges, Lem, Calvino, los hermanos Strugatski, Eco, Sacks, Pizarnik, G.R.R. Martin, incluso a la película ciberpunk Blade Runner, además de las ya citadas con anterioridad -Cervantes, Hoffmann, Shelley, Meyrink, Wells, Lovecraft- y de las que reseña en su "Escolio" -Cavafis, Girondo, Sabine, Gómez de la Serna-, entre otras. 
No se ha de olvidar, por otra parte, el empleo de la intratextualidad, ya que $E l$ gran imaginador, gestado durante muchos años en convivencia con el resto de publicaciones de Muñoz Rengel, ofrece una multiplicación de posibilidades de desarrollo de las mismas historias en variantes tan originales como perturbadoras. Reaparecen las ideas borgianas presentes en 88 Mill Lane, así como el motivo de las reliquias y de las ideas ilusorias que se extienden como una epidemia. Se revisita el viaje desde el dato histórico hacia lo prospectivo que constituía el eje de De mecánica y alquimia. Junto a la inspiración en escenarios reales, otros puntos en común con dicho libro son: los autómatas, la metáfora de la esponja de Kalymnos, los insectos, el interés tanto por los artilugios mecánicos como por la alquimia, los homenajes a los tratados de la historia de la ciencia europea, así como a seres creados artificialmente, a Verne, a Wells y al fantástico borgiano, y, sobre todo, a la figura del escritor incomprendido y adelantado a su tiempo. Con El asesino hipocondríaco le hermana el humor, la configuración peculiar del protagonista y la visión de trastornos inconcebibles y raras afecciones. Asimismo, la idea del constructo de realidad entendida como una derivación de la ficción se abordaba en El sueño del otro. Por su parte, el particular lenguaje de los alienígenas que invaden Estambul en la novela, definido como una gramática gramínea, enlaza con el sistema de escritura extraterrestre de "London Gardens" (2012) -cuento steampunk o retrofuturista-, equiparable al código criptográfico de una rosa común y que conlleva cambios que modifican el rumbo de la ciencia y de la Historia. También los seres fabulosos y de otros planetas destacaban en El libro de los pequeños milagros. En suma, todos los títulos citados comparten con El gran imaginador, en mayor o menor grado, el interés por la inconsistencia de nuestra realidad, así como por los contenidos históricos, filosóficos y científicos mezclados con la fabulación y con el sueño.

En conclusión, se puede aseverar que la obra de Muñoz Rengel, a pesar de la originalidad de cada una de sus publicaciones, mantiene desde sus inicios una gran solidez y un espíritu común como guía. Su singular poética tiene su germen en la mixtura de categorías próximas a las fronteras de lo fantástico y de los conocidos como géneros de consumo o populares, hecho que no está reñido con un resultado erudito, intelectual y de calidad. Como demuestra Gregori (2015), lo irreal no es contrario al desarrollo de una dimensión política, de un destacado componente ideológico. De tal modo, en El gran imaginador conviven lo lúdico y la defensa de la imaginación con la profundización en una realidad concreta, la del mapa físico y político de la Europa moderna y del Mediterráneo, marcada por la convivencia de culturas, etnias y religiones, la quema de libros, el tráfico de reliquias, los avances en materia filosófica, teológica, astrológica, biológica, botánica e histórica.

La defensa que Popoulos hace de la imaginación como refugio liberador y como instrumento que nos salva de los aspectos más negativos de la realidad vivida es rotunda, como también lo es su testimonio, en muchos casos rodeado de humor inteligente y fina ironía, sobre el simulacro y las falsificaciones. Desde ese ideario se 
entienden los guiños a la posibilidad de que el libro redactado en un cuaderno de pergamino por Popoulos en Praga sea el misterioso manuscrito Voynich, de escritura indescifrable y autoría incierta todavía en la actualidad. A ello contribuye también que otra de las identidades de Popoulos sea la de Pietro Averlino, persona real que fue ridiculizada en su época por su tratado de arquitectura y que ha sido relacionada en fechas recientes con la autoría del enigmático manuscrito.

En esta novela las propuestas de una imaginación multidimensional, que adopta una nueva mirada y explica la realidad y la Historia tanto en lo minúsculo como en lo panorámico, encajan en un medido engranaje que conduce a un sentido superior, al igual que lo hacen las diferentes vías de expresión que ofrecen lo fantástico y los géneros próximos a esta vertiente. Su planteamiento laminado genera un libro semejante a los admirados tanto por Muñoz Rengel (2016) como por todos los amantes de la literatura, textos "que encierran vidas y mundos enteros, que nos transportan y nos embriagan y hacen vivir un tiempo regalado" (p. 453). El interés por el mundo de las ideas, así como las reflexiones metaliterarias de las últimas páginas -relativas al proceso de elegir las civilizaciones, los escenarios, los personajes, las emociones y el lenguaje con el cual asombrar al mundo- remiten a los propios esfuerzos de Muñoz Rengel por incluir todo lo insólito y extraordinario que convive en su genio creativo, arriesgando y rompiendo esquemas mediante la disolución de fronteras entre lo fantástico y otros géneros aledaños. 


\section{REFERENCIAS BIBLIOGRÁFICAS}

Abate, S. (1997). A medio siglo del realismo mágico: balance y perspectivas. Anales de Literatura Hispanoamericana, 261, 145-159.

Abello Verano, A. (2016). Narrativas de lo (in)cierto: consideraciones sobre lo fantástico en la cuentística española actual. En N. Álvarez, A. Abello \& S. Fernández (eds.), Territorios de la imaginación: poéticas ficcionales de lo insólito en España y México (pp. 17-33). León: Área de Publicaciones de la Universidad de León.

Álvarez Méndez, N. (2013). Presentación. Brumal. Revista de Investigación sobre lo Fantástico, $1(2), 195-200$.

- (2016). Conversación con escritores de la imaginación: Patricia Esteban Erlés, Alberto Chimal y Juan Jacinto Muñoz Rengel. En N. Álvarez, A. Abello \& S. Fernández (eds.), Territorios de la imaginación: poéticas ficcionales de lo insólito en España y México (pp. 51-68). León: Área de Publicaciones de la Universidad de León.

Ceserani, R. (1999). Lo fantástico. Madrid: Visor.

Coates, P. (1988). The Double and the Other. Londres: McMillan.

Díez, J. \& Moreno, F. A. (2014). Historia y antología de la ciencia ficción española. Madrid: Cátedra.

Gregori, A. (2015). La dimensión política de lo irreal: el componente ideológico en la narrativa fantástica española y catalana. Poznań: Wydawnictwo Naukowe UAM.

Jackson, R. (1981). Fantasy: The Literature of Subversion. Londres \& Nueva York: Routledge.

Llarena, A. (1997). Un balance crítico: la polémica del realismo mágico y lo real maravilloso americano (1955-1993). Anales de Literatura Hispanoamericana, 261, 107-117.

Moreno, F. A. (2010). Teoría de la Literatura de Ciencia Ficción. Poética y Retórica de lo Prospectivo. Vitoria: Portal Editions.

Muñoz, M. A. (2011). La familia del aire. Entrevistas con cuentistas españoles. Madrid: Páginas de Espuma.

Muñoz Rengel, J. J. (2005). 88 Mill Lane. Granada: Alhulia.

- (2009). De mecánica y alquimia. Madrid: Salto de Página.

- (2012a). El asesino hipocondríaco. Barcelona: Plaza \& Janés.

- (2012b). London Gardens. En F. J. Palma (ed.), Steampunk: antología retrofuturista (pp. 113-147). Madrid: Fábulas de Albión.

- (2013a). El sueño del otro. Barcelona: Plaza \& Janés.

- (2013b). El libro de los pequeños milagros. Madrid: Páginas de Espuma.

- (2015). Lo fantástico como indagación: la ficción como herramienta del conocimiento. En N. Álvarez \& A. Abello (eds.), Espejismos de la realidad: percepciones de lo insólito en la literatura española (siglos XIX-XXI) (pp. 19-22). León: Área de Publicaciones de la Universidad de León.

- (2016). El gran imaginador o la fabulosa historia del viajero de los cien nombres. Barcelona: Plaza \& Janés.

Reisz, S. (2001). Las ficciones fantásticas y sus relaciones con otros tipos ficcionales. En D. Roas (ed.), Teorías de lo fantástico (pp. 193-221). Madrid: Arco/Libros.

Roas, D. (2011). Tras los límites de lo real: una definición de lo fantástico. Madrid: Páginas de Espuma.

- (2014). El reverso de lo real: formas y categorías de lo insólito. En J. Ordiz (ed.), Estrategias y figuraciones de lo insólito en la narrativa mexicana (siglos XIX-XXI) (pp. 9-29). Oxford: Peter Lang. 
- (2015). Lo fantástico en la narrativa española actual. En N. Álvarez \& A. Abello (eds.), Espejismos de la realidad: percepciones de lo insólito en la literatura española (siglos XIX-XXI) (pp. 221-232). León: Área de Publicaciones de la Universidad de León.

Roas, D., Álvarez, N. \& García, P. (2017). Narrativa 1980-2015. En D. Roas (dir.), Historia de lo fantástico en la cultura española contemporánea (1900-2015) (pp. 195-214). Madrid \& Frankfurt am Main: Iberoamericana \& Vervuert. 